\title{
AN INVESTIGATION OF DIFFUSE FAILURE MODES IN UNDRAINED TRIAXIAL TESTS ON LOOSE SAND
}

\author{
JACQues DesRUeSi) and IOANNIS-ORESTIS GeORGOPOUlos ${ }^{\mathrm{ii})}$
}

\begin{abstract}
In this paper we present an experimental study performed as an attempt to exhibit non-localized, diffuse failure deformation modes in sand specimens submitted to test conditions leading to unstable failure. In particular, we are interested in diffuse modes which may appear in common triaxial compression tests on undrained loose sand specimens. A special series of triaxial compression tests are reported. These tests resemble the common triaxial compression tests but are modified in such a way that after the peak in the stress-strain curve, test control is changed from straincontrol to stress-control. More precisely, a special kind of load-control is used, based on an original device which allows to recover displacement-control after a dynamic step in the post-peak regime. It is shown that the control used allows for the observation of the failure modes occurring in the unstable branch of the test.
\end{abstract}

Key words: diffuse failure, dynamic instability, localization, shear band, stress-strain controlled triaxial compression tests (IGC: D6/F6)

\section{INTRODUCTION}

A proper description and understanding of failure in geomaterials is a major concern in natural hazard mitigation. Localized failure is known to control a number of catastrophic ruptures observed in the field (among other references, "Failure" by Scott (1987), but there are cases in which rupture seems to concern all or a large part of the volume of the material involved in the problem. In the laboratory, a number of experimental studies, e.g. Vardoulakis et al. (1978, 1985), Drescher (1982), Han (1991), di Prisco (2000), Desrues et al. (1985, 1989, 2004), Tatsuoka et al. (1986, 1990), Yoshida (1994), Kato et al. (2001), Arthur et al. (1977, 1982), Finno et al. $(1995,1996)$ and others, have shown that strain localization is observed in a large range of test conditions for geomaterials. In dense sand specimens tested under low to moderate mean effective stress, shear bands are likely to occur even in well refined tests, including slenderness reduction and careful end lubrication (Desrues, 1996, 2004). In loose sand and elevated mean effective stress, localization can be delayed significantly but it remains the final deformation mode (Desrues, 1989). Shear bands are observed also in undrained tests, in which the deformation is constrained to an isochoric deformation mode due to the pore fluid trapped in the specimen (Han, 1991), (Mokni, 1999). Theoretical studies in the framework of Bifurcation Theory-Rice (1976), Vardoulakis (1995), Desrues and Chambon (1989), Chambon et al. (2000), Desrues and
Chambon (2000) and others- have shown that shear banding can be predicted solely on the basis of the constitutive law that describe the behaviour of the material. On the other hand, other theoretical investigations-Darve et al. (2000), Nova (1994) - suggest that in some loading conditions, loss of stability can occur for effective stress states far before the plastic failure stress condition or the shear banding bifurcation criterion is met, and lead to diffuse rather than localized failure. Gajo (2000, 2004) investigated theoretically and experimentally the onset of the instability in saturated, loose sand samples and analyzed the influence of loading system compliance on the instability under stress-controlled conditions. The tests were performed under drained conditions rather than undrained, but special loading paths were followed, starting from an anisotropic state of stress $\left(q, p^{\prime}\right)$ with $q$ deviatoric stress and $p^{\prime}$ mean effective stress. The loading paths involved imposed increase of the pore pressure in order to reduce $p^{\prime}$ at constant $q$, or other stress path control involving a decrease of $p^{\prime}$ as an intermediate phase in the test. These tests lead to catastrophic failure, or limited failure with a dynamic strain jump, depending on the deviatoric loading system (dead loads or pneumatic piston). This study shares some points with the one discussed in the present paper, but the latter was concerned more with the question of diffuse or localized failure. Vaid and Sivathayalan (2000) in a very detailed study of the fundamental factors that affect the observed liquefaction susceptibility of saturated sands, discuss among other factors the effect of loading tech-

i) Directeur de Recherche, CNRS-Université de Grenoble, France.

ii) PhD Student, National Technical University of Athens, Greece (IGeorgopoulos@mechan.ntua.gr).

The manuscript for this paper was received for review on November 12, 2004; approved on July $26,2006$.

Written discussions on this paper should be submitted before May 1, 2007 to the Japanese Geotechnical Society, 4-38-2, Sengoku, Bunkyo-ku, Tokyo 112-0011, Japan. Upon request the closing date may be extended one month. 


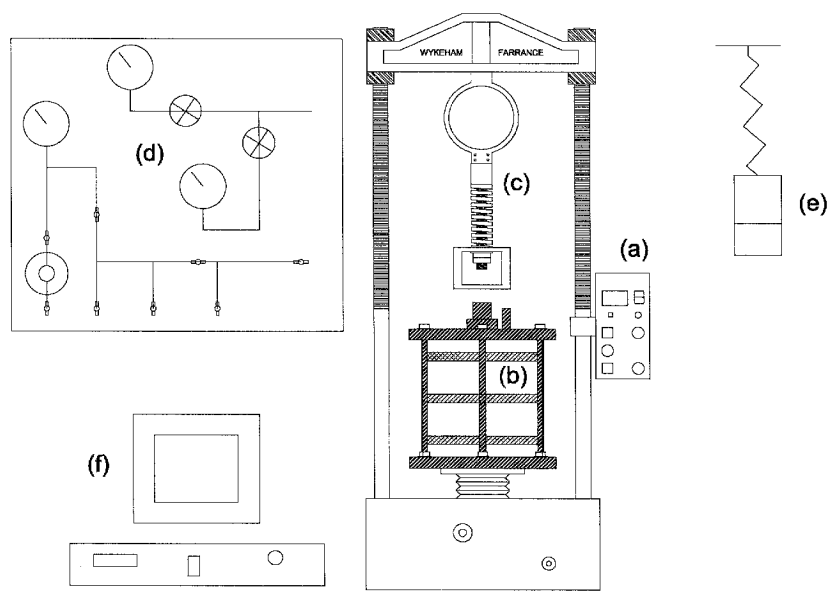

Fig. 1. General synopsis of the triaxial installation

niques on the apparatus-specimen interactions in monotonic liquefaction tests. The techniques studied include strain-controlled, dead weight, pneumatic piston and pneumatic piston plus a volume booster. However, no experimental information is given about localized or nonlocalized nature of the deformation process during the unstable deformation phase, neither in Gajo $(2000,2004)$ nor in Vaid and Sivathayalan (2000). In fact, deformation modes can hardly be characterized experimentally since they are supposed to occur along unstable loading branches for which the brutal acceleration of the deformation process does not allow to observe the transient deformation modes of the specimen.

In the following we present a simple, prospective, experimental study performed as an attempt to observe either localized or non-localized, diffuse failure deformation modes in sand specimens submitted to tests conditions typically leading to unstable failure. A special test device is used to let the system jump into the dynamic mode after load peak, but only for a short while. After that, displacement control is restored, allowing for a characterization of the kinematics the specimen underwent during the unstable, quasi instantaneous part of the path.

\section{EXPERIMENTAL SET-UP}

In the following, a short description of the triaxial apparatus used is given and the special device developed is described. Further information and details on the procedure of triaxial testing for soils can be found in soil mechanics handbooks, e.g. Bishop and Henkel (1957), or more recently Bardet (1997), Head (1992).

The triaxial apparatus used is a basic strain-controlled axisymmetric triaxial apparatus. Figures 1 and 2 show the main features of the installation. It is made of two independent components, namely (a) a loading frame $50 \mathrm{kN}$ in capacity, manufactured by Wykeham Farrance, including a frame and a motorized screw jack controlling the displacement of the bottom platen of the system and (b) a home-made triaxial cell. The displacement rate can

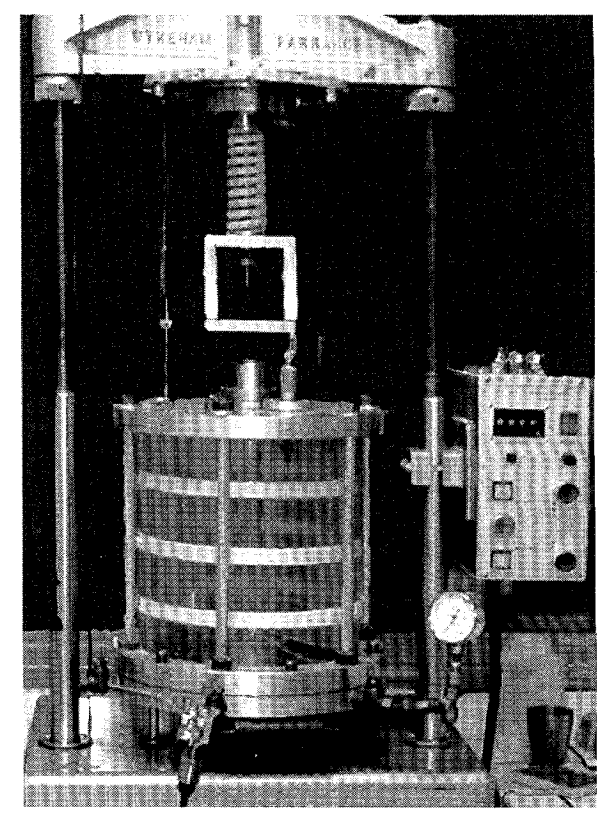

Fig. 2. General view of the triaxial installation

be adjusted in the range $0.0001-5.9999 \mathrm{~mm} / \mathrm{min}$. The axial load is measured by a load cell/ring (c), whose capacity is $\sim 30 \mathrm{kN}$. An LVDT is used for measuring the axial deformation of the specimen and it is placed on the top of the cell. The cell pressure is controlled by a mechanical valve and the pore pressure by a mercury pot system (e), which allows at the same time for volume change measurements during the drained phases of the tests (consolidation). Both the cell pressure and the pore pressure are measured by pressure gauges. All the measurements are recorded using a data acquisition system under computer control (f).

In order to achieve the special test control described above in section 1, a slight modification was made to the triaxial apparatus. The modification consists of the installation of a spring between the piston of the cell and the load cell/ring. The purpose of such a modification mainly stems from the necessity to be able to control the stress and not the strain in a triaxial test, after the peak in the stress-strain curve in the softening region. The described system consists of an elastic spring of $K_{\mathrm{r}}$ stiffness, which has a metal box on one of its ends. The metal box is connected to the one end of the spring via a bolt and a nut. The bolt is screwed at one end of a piston. The spring itself can freely slide along the piston, which goes through the spring. What can prevent the spring from sliding is a nut at the one end of the piston. A metal box is used to transfer the axial forces from the specimen through the spring up to the load cell/ring. At the same time the box with the nut serves as a regulator for the pre-stress level of the elastic spring. This means that, by keeping the other end of the spring fixed (i.e. screwed at the load cell) and by screwing the nut at the other end, one can compress the spring at a desired level. This will later on prove out to be useful. Figure 3 shows a typical view of the described system. A photo of this system is 


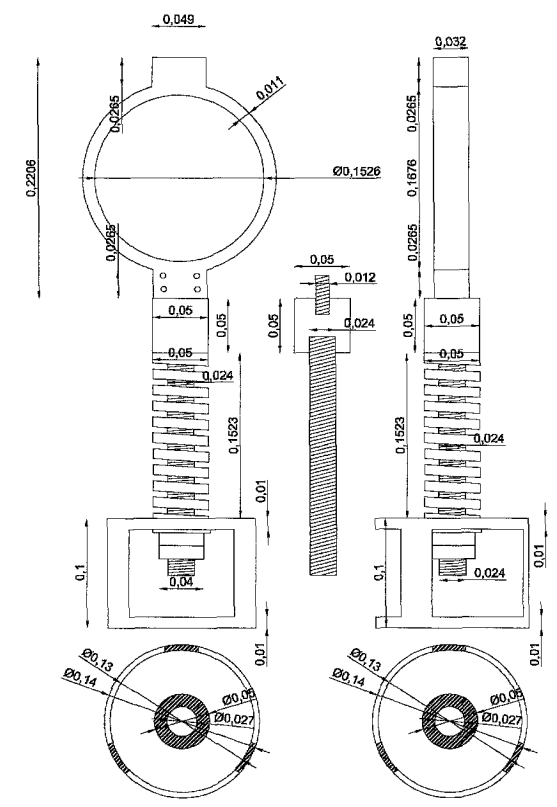

Fig. 3. Side view of the spring system

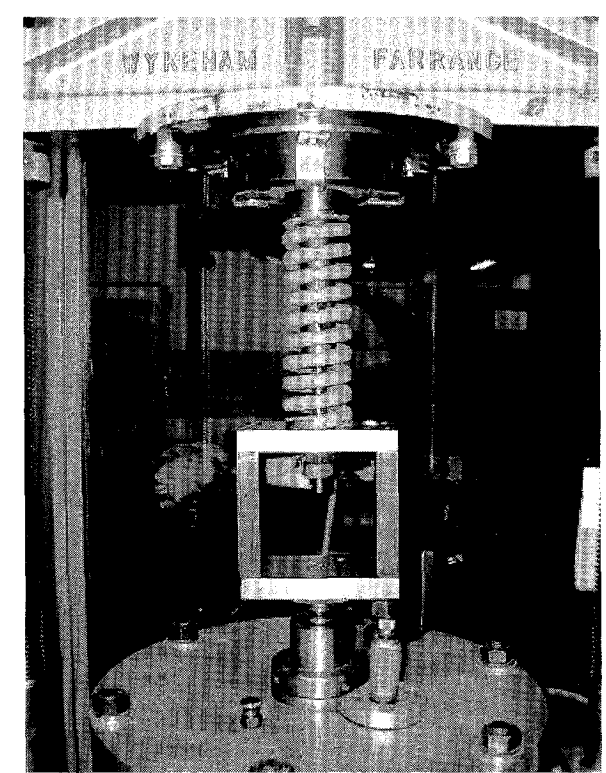

Fig. 4. Metal box, nut, elastic spring and load cell

also given in Fig. 4.

The device works in the following way: as long as the load transmitted to the spring-box system is lower than the pre-stress level, nothing happens to the spring: the system behaves as a rigid block. As soon as the axial load exceeds the pre-stress level, the spring starts to compress, i.e. it stores additional elastic energy. When the instability condition for the spring-specimen system is reachedthis condition is discussed in detail in section 3, the system jumps into a dynamic mode and the spring releases the energy stored by stretching back. However, the box does not allow more energy release than the amount stored after the pre-stress level was over passed. So the dynamic part of the test is limited in terms of specimen deformation, depending on the pre-stress level.

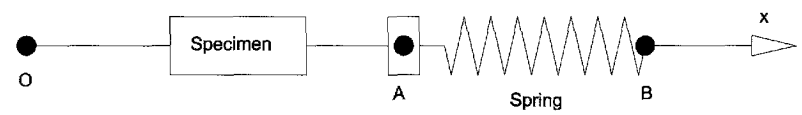

Fig. 5. Schematics of the specimen-spring system

\section{INSTABILITY CONDITION FOR THE SPECIMEN- SPRING SYSTEM}

Let us consider the system specimen-spring described in Fig. 5. The force applied by the specimen on point A is denoted as $F_{\mathrm{Spe} / \mathrm{A}}$, and the force applied by the spring on point $\mathrm{A}$ is denoted as $F_{\mathrm{Spr} / \mathrm{A}}$. The response of the specimen depends on the history of $x_{\mathrm{A}}$, including the present state:

$$
F_{\mathrm{Spe} / \mathrm{A}}=f\left(x_{\mathrm{A}}-x_{\mathrm{O}}, \ldots\right)=f\left(x_{\mathrm{A}}, \ldots\right)
$$

with $x_{O}=0$.

The response of the spring is linear, with a constant stiffness $K_{\mathrm{r}}$ :

$$
F_{\mathrm{Spr} / \mathrm{A}}=-K_{\mathrm{r}}\left(x_{\mathrm{A}}-x_{\mathrm{B}}\right)
$$

Assuming that the mass of the system is concentrated at point $\mathrm{A}$, the fundamental equation of dynamics reads:

$$
F_{\mathrm{Spe} / \mathrm{A}}+F_{\mathrm{Spr} / \mathrm{A}}=m \ddot{x}_{\mathrm{A}}
$$

Using Eqs. (1) and (2) in (3):

$$
f\left(x_{\mathrm{A}}, \ldots\right)-K_{\mathrm{r}}\left(x_{\mathrm{A}}-x_{\mathrm{B}}\right)=m \ddot{x}_{\mathrm{A}}
$$

Let us consider a given state which has been reached following a quasistatic loading path. Up to this state, the acceleration $\ddot{x}_{\mathrm{A}}$ is zero.

$$
f\left(x_{\mathrm{A}}, \ldots\right)-K_{\mathrm{r}}\left(x_{\mathrm{A}}-x_{\mathrm{B}}\right)=0
$$

The system becomes unstable as soon as a small perturbation of the system does not lead to small oscillations (which in practice will decay due to imperfections like frictional and/or viscous effects), but to increasing displacement (either oscillating or monotonous) from the rest position $x_{\mathrm{A}}$. Adding a small incremental displacement $u_{\mathrm{a}}$ to $x_{\mathrm{a}}$ in Eq. (3) we get:

$$
f\left(x_{\mathrm{A}}+u_{\mathrm{A}}, \ldots\right)-K_{\mathrm{r}}\left(x_{\mathrm{A}}+u_{\mathrm{A}}-x_{\mathrm{B}}\right)=m\left(\ddot{x}_{\mathrm{A}}+\ddot{u}_{\mathrm{A}}\right)=m \ddot{u}_{\mathrm{A}}
$$

Substracting Eq. (4) from (5) gives:

$$
f\left(x_{\mathrm{A}}+u_{\mathrm{A}}, \ldots\right)-f\left(x_{\mathrm{A}}, \ldots\right)-K_{\mathrm{r}} u_{\mathrm{A}}=m \ddot{u}_{\mathrm{A}}
$$

The expansion of $f\left(x_{\mathrm{A}}+u_{\mathrm{A}}, \ldots\right)$ is a difficult task, as soon as non-elastic behavior is considered, due to the strong non-linearity of the constitutive equation. The study of the stability of an equilibrium state can be restricted to the beginning of the movement after a perturbation of the equilibrium, with a discussion of the different cases with respect to loading and unloading.

As illustrated in Fig. 6, in the general case (not elastic), the specimen has two possible responses. Depending on the sign of the incremental stretch undergone, with respect to the state, we have loading for continued deformation process, and unloading for reverse deformation.

Considering that the present equilibrium state is a 


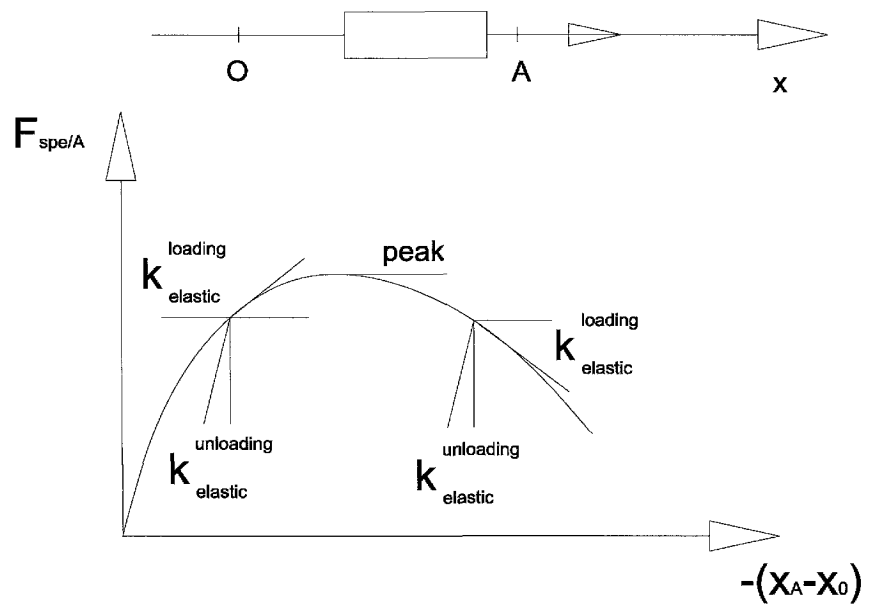

Fig. 6. Force-stretch characteristics of the specimen, with loadingunloading branches in pre-peak and post-peak regime

compression state, the initial phase of later movement will be either loading, which corresponds to negative $u_{\mathrm{A}}$, or unloading, which corresponds to positive $u_{\mathrm{A}}$. Depending on the sign of $u_{\mathrm{A}}$, the load increment corresponding to a small incremental displacement $u_{\mathrm{A}}$ will read:

$$
\begin{array}{lll}
u_{\mathrm{A}}<0 & \text { loading } & f\left(x_{\mathrm{A}}+u_{\mathrm{A}}\right)-f\left(x_{\mathrm{A}}\right)=-K_{\mathrm{e}}^{\mathrm{l}} u_{\mathrm{A}} \\
u_{\mathrm{A}}>0 & \text { unloading } & f\left(x_{\mathrm{A}}+u_{\mathrm{A}}\right)-f\left(x_{\mathrm{A}}\right)=-K_{\mathrm{e}}^{\mathrm{u}} u_{\mathrm{A}}
\end{array}
$$

with $K_{\mathrm{e}}^{1}$ the tangent stiffness of the specimen for loading, and $K_{\mathrm{e}}^{\mathrm{u}}$ the tangent stiffness of the specimen for unloading.

The equation for $u_{\mathrm{A}}$ (denoted $u$ for concision) during the initial phase of the movement is then:

$$
m \ddot{u}+\left(K_{\mathrm{e}}+K_{\mathrm{r}}\right) u=0
$$

with $K_{\mathrm{e}}=K_{\mathrm{e}}^{\mathrm{l}}$ or $K_{\mathrm{e}}^{\mathrm{u}}$ depending on the sign of $u$.

Classically the solution of this differential equation is looked for in the form:

$$
u=e^{i \omega t}
$$

then $\ddot{u}=-\omega^{2} u$ and Eq. (7) becomes:

$$
\left(K_{\mathrm{e}}+K_{\mathrm{r}}-\omega^{2}\right) u=0
$$

and for non-zero $u$ :

$$
K_{\mathrm{e}}+K_{\mathrm{r}}-\omega^{2}=0
$$

The two roots of the equation (possibly complex) are:

$$
\omega= \pm \sqrt{\frac{K_{\mathrm{e}}+K_{\mathrm{r}}}{m}}
$$

and the general solution of the Eq. (7) is:

$$
u=A e^{i \sqrt{\left(K_{\mathrm{e}}+K_{\mathrm{r}}\right) / m} t}+B e^{-i \sqrt{\left(K_{\mathrm{e}}+K_{\mathrm{r}}\right) / m} t}
$$

Let us assume that the initial conditions (arbitrary perturbation applied) are: for $t=0, u=u_{0}$ and $\dot{u}=0$. For $t=0$ we have:

$$
e^{i \sqrt{\left(K_{\mathrm{e}}+K_{\mathrm{r}}\right) / m} t}=e^{-i \sqrt{\left(K_{\mathrm{e}}+K_{\mathrm{r}}\right) / m} t}=1
$$

then

$$
A e^{i \sqrt{\left(K_{\mathrm{e}}+K_{\mathrm{r}}\right) / m} t}+B e^{-i \sqrt{\left(K_{\mathrm{e}}+K_{\mathrm{r}}\right) / m} t}=A+B
$$

and using Eq. (8) for $t=0$ we get:

$$
A+B=u_{0}
$$

On the other hand, using $\dot{u}=0$ for $t=0$ gives:

$$
\begin{aligned}
\dot{u} & =i \sqrt{\frac{K_{\mathrm{e}}+K_{\mathrm{r}}}{m}}\left[A e^{i \sqrt{\left(K_{\mathrm{e}}+K_{\mathrm{r}}\right) / m} t}-B e^{-i \sqrt{\left(K_{\mathrm{e}}+K_{\mathrm{r}}\right) / m} t}\right] \\
& =i \sqrt{\frac{K_{\mathrm{e}}+K_{\mathrm{r}}}{m}}[A-B]=0
\end{aligned}
$$

then $A-B=0$

These conditions on $A$ and $B$ can be met with $A=B=$ $u_{0} / 2$, then we have from Eq. (8):

$$
u=\frac{u_{0}}{2}\left[e^{i \sqrt{\left(K_{\mathrm{e}}+K_{\mathrm{r}}\right) / m} t}+e^{-i \sqrt{\left(K_{\mathrm{e}}+K_{\mathrm{r}}\right) / m} t}\right]
$$

It is time now to discuss the respective values of the tangent stiffness of the specimen $K_{\mathrm{e}}$ and the stiffness of the spring $K_{\mathrm{r}}$. If the specimen exhibits a characteristic load-stretch response with a peak followed by a decrease in the load like in Fig. 6, then one has to distinguish prepeak from post-peak states, and in both of them loading from unloading (in the sense defined above).

$$
\begin{array}{lllll}
\text { Before Peak: } & u<0 & \text { loading } & K_{\mathrm{e}}=K_{\mathrm{e}}^{\mathrm{l}}>0 & \text { (a) } \\
& u>0 & \text { unloading } & K_{\mathrm{e}}=K_{\mathrm{e}}^{\mathrm{u}}>0 & \text { (b) } \\
\text { After Peak: } & u<0 & \text { loading } & K_{\mathrm{e}}=K_{\mathrm{e}}^{1}<0 & \text { (c) } \\
& u>0 & \text { unloading } & K_{\mathrm{e}}=K_{\mathrm{e}}^{\mathrm{u}}>0 & \text { (d) }
\end{array}
$$

In cases (a), (b), (d), we have $K_{\mathrm{e}}+K_{\mathrm{r}}>0$. Then the square root $\sqrt{\left(K_{\mathrm{e}}+K_{\mathrm{r}}\right) / m}$ is real and the general solution Eq. (9) of the differential equation involves only imaginary exponents. We have:

$$
u=u_{0} \cos \left(\sqrt{\frac{K_{\mathrm{e}}+K_{\mathrm{r}}}{m} t}\right)
$$

which is an oscillating movement, indicating that perturbations do not grow. The equilibrium is stable. However, in case (c), $K_{\mathrm{e}}^{1}+K_{\mathrm{r}}$ can be negative if: $K_{\mathrm{e}}^{\mathrm{l}}<-K_{\mathrm{r}}$ which means that the tangent stiffness of the specimen is negative, with a modulus higher than the stiffness of the spring. Then

$$
\sqrt{\frac{K_{\mathrm{e}}^{1}+K_{\mathrm{r}}}{m}}=\sqrt{i^{2} \frac{\left\|K_{\mathrm{e}}^{1}+K_{\mathrm{r}}\right\|}{m}}=i \sqrt{\frac{\left\|K_{\mathrm{e}}^{1}+K_{\mathrm{r}}\right\|}{m}}
$$

and Eq. (9) becomes:

$$
u=u_{0} / 2\left[e^{-\sqrt{\left\|K_{\mathrm{e}}^{1}+K_{\mathrm{t}}\right\| / m} t}+e^{\sqrt{\left\|K_{\mathrm{e}}^{1}+K_{\mathrm{r}}\right\| / m} t}\right]
$$

in which the second term grows exponentially with time, while the first decays exponentially. Neglecting the first one we have:

$$
u=u_{0} / 2 e^{\sqrt{\| K_{\mathrm{c}}^{1}+K_{\mathrm{r}} \mid \mathrm{i} / m} t}
$$

We can conclude that a sufficient condition for instability of the system is:

$$
K_{\mathrm{e}}<-K_{\mathrm{r}}
$$


Consolidated undrained triaxial compression test (Hostun $\mathrm{S}_{28}$ )

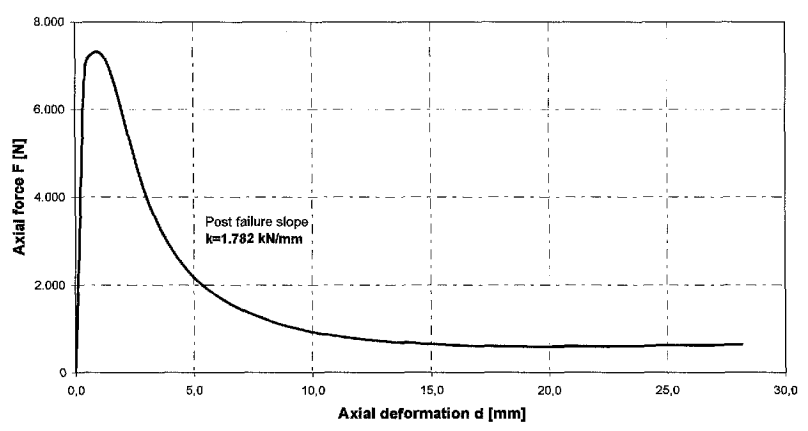

Fig. 7. Specimen's force-displacement curve for loose Hostun sand $S_{28}$

\section{Spring Stiffness Selection}

One major point that is worth mentioning is the selection of the elastic spring. The main purpose of this experimental investigation is to be able to be stress-controlled after the peak, in the stress-strain curve of the soil specimen, in a strain-controlled test. In order to achieve this, we have to choose a spring with stiffness matching Eq. (12), which can be reformulated as: $K_{\mathrm{r}}<-K_{\mathrm{e}}$ keeping in mind that $K_{\mathrm{e}}$ is the slope of the load-displacement curve of the specimen in its softening branch, i.e. essentially a negative quantity, while the rigidity of the spring $K_{\mathrm{r}}$ is essentially a positive one. This value of $K_{\mathrm{e}}$ is assumed to govern the post-peak behavior of the specimen considered as a whole, in its softening branch, as long as the test remains non-dynamic (negligible acceleration, low strain rate). Indeed, whatever the deformation of the specimen is, diffuse or localized, its post-peak axial force-displacement characteristics can be characterized by a $K_{\mathrm{e}}$ value for the specimen considered as a structure. We discuss the behavior of the system spring-specimen with respect to the ratio of $K_{\mathrm{e}}$ and $K_{\mathrm{s}}$.

To determine the relevant stiffness, we performed a strain-controlled undrained triaxial compression tests on loose Hostun $S_{28}$ sand. The steepest (negative) post-peak inclination of the curve in the axial force-deformation diagram was found to be $K_{\mathrm{e}}=-1.782 \mathrm{kN} / \mathrm{mm}$ (see Fig. 7). Thus, in order to fulfill inequality 12 sooner or later after the peak, the stiffness of the elastic spring which was selected, was smaller than $K_{\mathrm{e}}\left(K_{\mathrm{r}}=0.257 \mathrm{kN} /\right.$ $\mathrm{mm})$.

The smaller the stiffness of the spring, the sooner will come the dynamic jump after the peak. Ideal load control (dead load) is equivalent to a spring with vanishing stiffness. In this case the instability would occur just at peak load, but practical difficulties would result from extremely large - virtually infinite indeed-deformation of the spring.

\section{Pre-stress Level Selection}

By using the aforementioned system of the metal boxbolt-nut at the one end of the spring, we can control the elastic energy that will be given to the specimen in the softening region. This is easily accomplished by screwing the nut at the one end of the spring, where the metal box is, up to a certain level, and by keeping the other end of the spring firmly screwed at the load cell. By this setout, we predefine the initial pre-stress level force of the spring. This means, in other words, that the spring will be prestressed up to a certain point from the very first beginning of the test, which will allow us later on to investigate various cases of diffuse modes of failure.

Let us now follow what happens if the spring is precompressed. In the beginning of the undrained triaxial compression test and up to the point where the axial load is less than the pre-stress force level, the spring will not be additionally compressed.

Up to now, the test itself resembles the common undrained triaxial compression test. As soon as the axial force is passed, this means that we have exceeded the pre-stress force level, the spring will start get compressed from its initial state.

At the peak in the load-displacement curve, $K_{\mathrm{e}}=0$ and the instability condition $K_{\mathrm{r}}<-K_{\mathrm{e}}$ is not met immediately (and cannot have been met before). After passing the peak in the stress-strain curve, $K_{\mathrm{e}}$ becomes negative, with an increasing absolute value $\left\|K_{\mathrm{e}}\right\|$. If the spring has been properly selected (proper stiffness $K_{\mathrm{r}}$ ), later or sooner the condition will be met. Then the system specimen-spring will start accelerating. The axial load continues to decrease and the spring to extend. However, when the initial pre-stress force is reached on this load-decreasing branch, the system of the metal box-bolt-nut prevents the spring from fully extending to its original length. From this point, the specimen will not receive any more energy from the spring. Depending on the conditions, the system may or may not return to a strain-controlled behavior. Indeed, although a part of the potential (elastic) energy transmitted to the system during the dynamic jump has been dissipated in plastic deformation, another part has been converted to kinetic energy. This part has to be dissipated by plastic deformation also, before the movement stops. Thus, depending on the pre-load level, the specimen may be completely destroyed in the subsequent movement, or recover some rigidity after the dynamic step-accelerating then decelerating phases.

In the below experimental analysis, an attempt to explore the various modes of failure is given, and the effect of the pre-stress force level to the failure mode is discussed.

\section{EXPERIMENTAL RESULTS}

\section{Testing Program}

A series of five undrained triaxial compression tests was performed in order to investigate the aforementioned diffuse modes of failure. Loose specimens prepared by moist tamping technique (5\% water content) from Hostun sand $S_{28}$ were subjected to undrained triaxial compression. According to previous work done by Han and Vardoulakis (1991), the preparation of sand specimens with the moist tamping technique inevitable leads to a stratification of the sand specimen. X-ray tomographies have clearly shown the existence of such layers inside the 
Table 1. Undrained triaxial compression tests in Hostun sand $S_{28}$

\begin{tabular}{cccccc}
\hline $\begin{array}{c}\text { No. } \\
\text { test }\end{array}$ & $\begin{array}{c}\text { Void } \\
\text { ratio } \\
e[-]\end{array}$ & $\begin{array}{c}\text { Porosity } \\
n[-]\end{array}$ & $\begin{array}{c}\text { Relative } \\
\text { density } \\
D_{\mathrm{r}}[\%]\end{array}$ & $\begin{array}{c}\text { Saturation } \\
\text { degree } \\
S_{\mathrm{r}}[\%]\end{array}$ & $\begin{array}{c}\text { Deformation } \\
\text { rate } \\
{[\mathrm{mm} / \mathrm{min}]}\end{array}$ \\
\hline CUSPR01 & 1.053 & 0.513 & -4.9 & 99.4 & 2.0 \\
CUSPR02 & 1.089 & 0.521 & -15.3 & 99.5 & 2.0 \\
CUSPR03 & 1.122 & 0.529 & -25.0 & 99.6 & Various rates \\
CUSPR04 & 1.121 & 0.528 & -24.5 & 99.6 & 1.0 \\
CUSPR05 & 1.140 & 0.533 & -30.2 & 99.7 & 1.0 \\
\hline
\end{tabular}

specimen. It is quite possible that the tested specimens possess some degree of orthotropy, but according to the results obtained from biaxial tests this stratification does not seem to influence the geometric characteristics of failure modes in a significant manner. Moreover, according to Han and Vardoulakis (1991), the observed shear band thickness does not seem to be related to the thickness of the layers. The ratio of height to diameter of the specimen was kept constant for all tests $(H / D=1, D=$ $100.0 \mathrm{~mm}$ ). Enlarged lubricated end platens were used both in top cap and pedestal. The application of the axial load was achieved through a loading ram, which came into contact with the top cap of the specimen through a sphere, in order to avoid the development of bending moments to the specimen. Elastic membranes of $0.40 \mathrm{~mm}$ thickness and $100.00 \mathrm{~mm}$ in diameter were used. An estimate of the minimum and maximum void ratio for the Hostun $S_{28}$ sand has been previously given by Combe (1998) $\left(e_{\min }=0.689, e_{\max }=1.036\right)$. The grain solid density $\rho_{\mathrm{s}}$ is $2.65 \mathrm{gr} / \mathrm{cm}^{3}$. The values of porosity $n$ and void ratio $e$ in Table 1 of the five specimens are calculated after the isotropic consolidation. All specimens were fully saturated (degree of saturation $S_{\mathrm{r}}=99.4 \div 99.7 \%$ ) and were isotropically consolidated up to $p^{\prime}=800 \mathrm{kPa}$, under a back pressure equal to $u=50 \mathrm{kPa}$. The confining pressure was kept constant during the test, equal to $\sigma_{\mathrm{c}}=850 \mathrm{kPa}$. Table 1 summarizes the five undrained triaxial compression tests. As far as strain rates are concerned, it should be stressed that, as soon as the pre-stress level selected is reached, the spring starts taking a part of the overall deformation rate imposed to the specimen-spring system; consequently the strain rate is reduced at this point, and the strain rate reduction with respect to the overall deformation rate is depending on the current tangent stiffness of the specimen. Consequently, since the stiffness of the specimen is monotonously decreasing along the test, the strain rate reduction is maximum when the pre-stress level is first reached, and decreases continuously from this point. The reduction vanishes at the peak stress, and becomes negative as the axial load start decreasing; i.e. the strain rate increases after the peak, due to the extension of the spring. It is easy to show that the strain rate becomes infinite when the criterion for a dynamic jump is met. As far as strain field monitoring is concerned, only direct naked-eye observation and photography of the outer surface of the cylindrical specimen was performed. However, a grid was drawn on the membrane before specimen preparation, in order to improve the efficiency
Table 2. Undrained triaxial compression tests in Hostun sand $S_{28}$

\begin{tabular}{cccc}
\hline No. test & $\begin{array}{c}\text { Mobilized friction } \\
\text { angle } \phi\end{array}$ & Pre-stress level & $\begin{array}{c}\text { Total } \\
\text { liquefaction }\end{array}$ \\
\hline CUSPR01 & $23.5^{\circ}$ & $140 \%$ & NO \\
CUSPR02 & $16.2^{\circ}$ & $85 \%$ & YES \\
CUSPR03 & $19.3^{\circ}$ & $88 \%$ & NO \\
CUSPR04 & $19.7^{\circ}$ & $98 \%$ & NO \\
CUSPR05 & $16.3^{\circ}$ & $96 \%$ & NO \\
\hline
\end{tabular}

of direct observation. The specimen was observed and photographed through the pressure cell during the test, but the last observation and photograph was done after cell removing. In case of well-developed shear band(s) reaching the outer boundary, the lines of the grid would have been distorted in the well-known figure illustrated by biaxial tests available in the literature (e.g. Desrues et al., 1985, 1989, 2004; Vardoulakis et al., 1978, 1985; Tatsuoka et al., 1986, 1990). This of course is not enough to guarantee that no localization took place inside the specimen, since inner localized deformation modes may exist, as shown by Desrues et al. (1996) using X-ray tomography, and confirmed later by Alshibly et al. (2003).

\section{Results}

As already mentioned a series of five undrained triaxial compression tests on loose Hostun sand $S_{28}$ were performed in order to verify the modes of failure in the softening region. The effect of the pre-stress force level of the spring to the total loss of the specimens' resistance is critically investigated. For this reason, five sand specimens were tested in undrained triaxial compression test, each one at a different pre-stress force level of axial force of the spring system. In this way we are able to control the energy given to the sand specimen after the peak in the softening region.

Table 2 summarizes the results of the triaxial tests. In Table 2 the first column is the No. of the test. The second column is the mobilized friction angle $\phi$ in degrees, while the third shows the ratio in percentage of the pre-stress force level of the spring to the maximum axial force measured during the test. If this percentage is equal to zero, this means that the spring is not at all pre-stressed, while a value of $100 \%$ or more means that the spring actually does not compress itself during the test, as the axial force can not go beyond the pre-stress force level of the spring. Finally, in the last column, we indicate whether or not the sand specimen lost completely its resistance, meaning, whether it was fully liquefied or not.

Figure 8 presents the shape of the five specimens in the final state. In four among the five tests, the specimens remained solid after the dynamic deformation phase, retaining the geometry of the final state after the dynamic jump. Only one test, namely CUSPR-02, was completely destroyed by the deformation underwent during the jump. The experimental program was conducted in the following way: first confirm that the over-pre-stressed spring does not play any role (test CUSPR-01). Then 


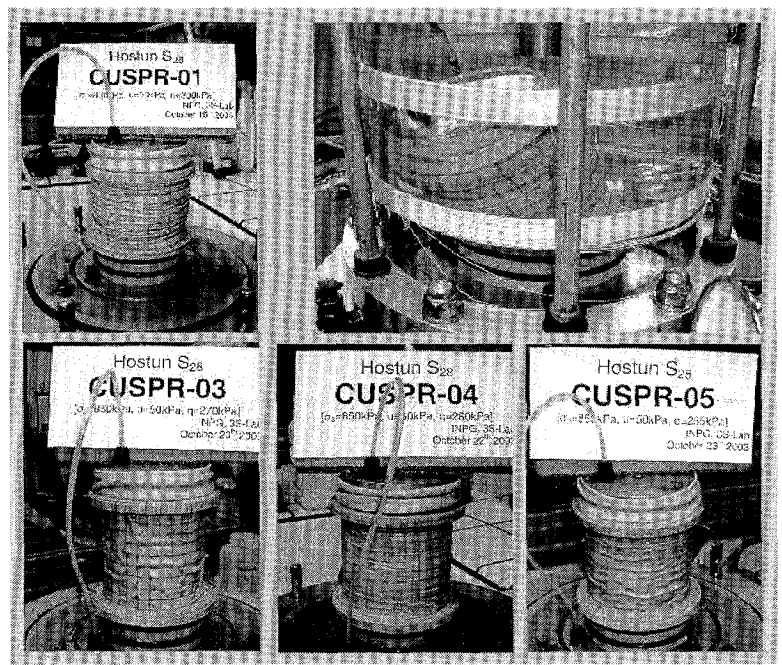

Fig. 8. Final configuration of the different specimens: The specimen without label on the photograph is test CUSPR-02

validate the efficiency of the spring in promoting a jump in the dynamic regime as soon as the theoretical condition in Eq. (12) is met (test CUSPR-02). Then find empirically the threshold in the pre-stress force to apply to the spring before testing, in order to avoid the complete destruction of the specimen after the dynamic jump. In fact, as explained in section 2, pre-stressing the spring allows to limit the amount of energy relaxed by the spring in the specimen after the start of the dynamic jump. The final shape of the specimens in the tests CUSPR-03, CUSPR04 and CUSPR-05, illustrated in Fig. 8, show that this condition could be met with pre-stress force above $88 \%$ of the peak load of the test. This exact value is not considered of particular significance. Indeed, both the variability of the specimen preparation and the uncertainty on the exact behaviour of the spring-box system near the pre-stress load, due to imperfections in the rather simple mounting of the experimental device, are responsible of not really well controlled experimental response of the system as the axial load approaches the pre-stressed load of the spring. However, the objective of the set of tests is fulfilled with the demonstration of the possibility (i) to trigger a dynamic jump in the post-peak part of the test and (ii) to control it to recover a deformed but still solid configuration of the specimen after the jump.

In the following, the stress-strain response of the different tests are discussed in detail. Figure 9 presents the deviatoric stress versus axial strain curves for the five tests. As mentioned above, due to the extra mechanical links introduced in the loading system by the spring device, some scatter appears in the curves. However, as long as the peak in the stress-strain curve is not reached, all curves are limited between two straight lines, as in the Fig. 9. Past the peak, the curves diverge each from others. In test CUSPR01, a progressive decay of the mobilised deviatoric stress with increasing axial strain is observed. In all other tests, a brutal drop occurs. This drop corresponds to the spring suddenly uncompressing. However, neither the peak load nor the delay after the

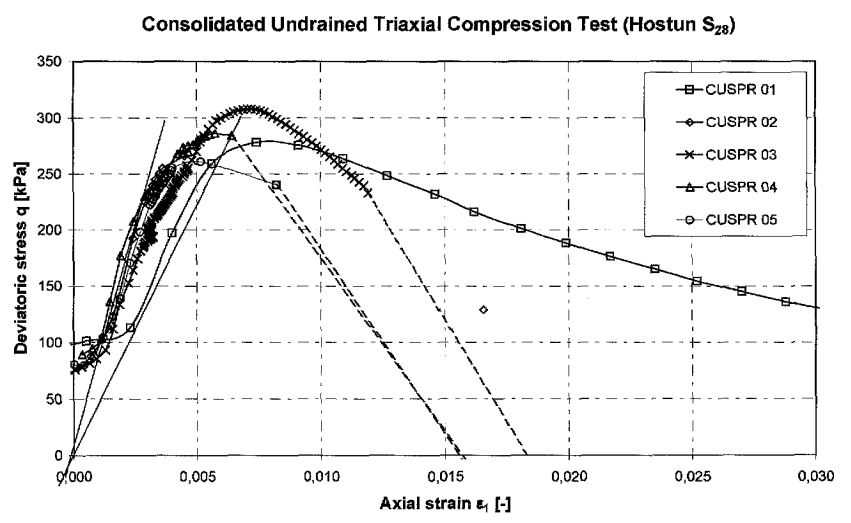

Fig. 9. Deviatoric stress versus axial strain response for all five specimens

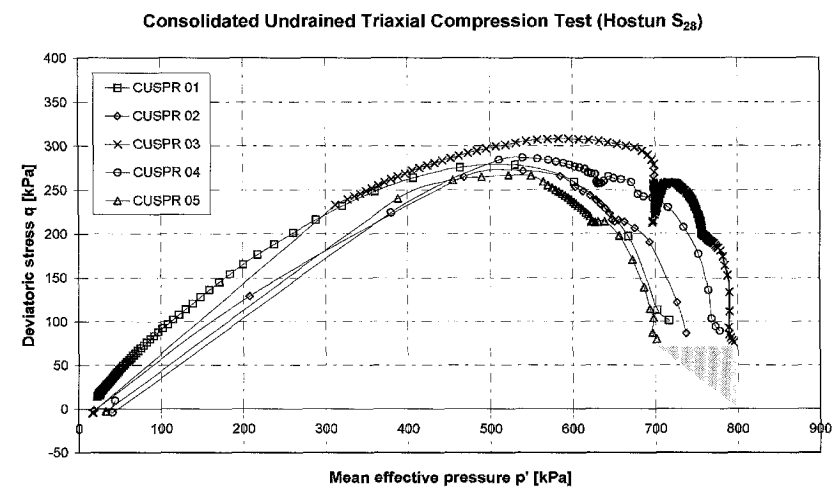

Fig. 10. Deviatoric stress versus mean effective stress for all five specimens

peak before the jump seem to be controlled by the pre-stress level. In fact, the imperfections in the tests are responsible for the variability of these features.

In the same way, $q$ versus $p^{\prime}$ curves shown in Fig. 10 indicate that, except in test CUSPR01, all the tests jump at some point after the peak, directly to the near-liquefied state with vanishing deviatoric stress and near-vanishing mean effective stress. The scatter in the curves is large, and it can be seen that the initial stage of the deviatoric loading, represented here by the gray triangle, is very confused. This is attributed to the fact that the isotropic compression of the very loose sand deposit obtained by moist tamping is unstable and induces large fluctuations in the undrained pore pressure at the beginning of the deviatoric loading. Even at larger deviatoric stress level, e.g. test CUSPR03 and CUSPR05 show sudden decreases of the mean effective stress $p^{\prime}$, not leading to the specimen collapse however since the deviatoric stress starts increasing again after a while.

Hence, all the tests did lead to more or less complete liquefaction. Figure 11 shows that in all the cases, pore pressure becomes almost equal to the cell pressure, indicating near complete loss of mechanical strength of the material of the specimen. In this figure, the pore pressure is plotted against strain of the specimen, which allows to see the different phases of the test. In only one test (CUSPR-02), the loss of mechanical strength is 


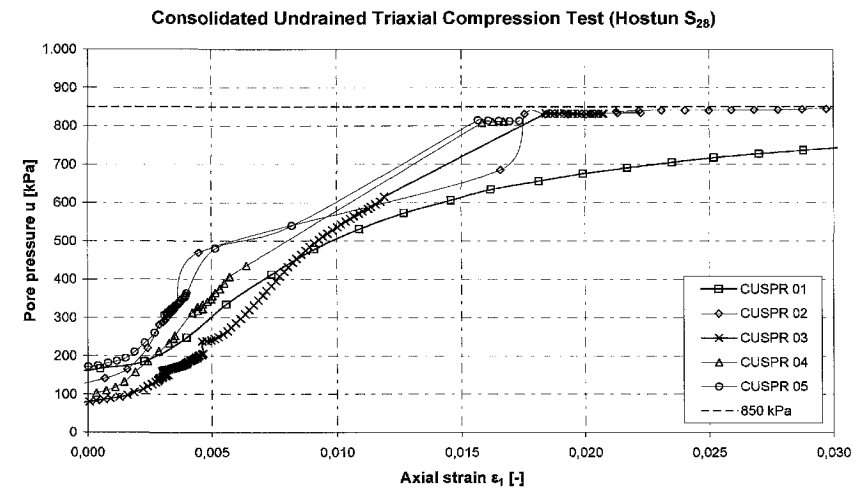

Fig. 11. Evolution of specimen's pore pressure against total axial deformation

total since the pore pressure reaches the cell pressure. However, the difference between the recorded cell pressure and pore pressure may not be the most relevant criterion to decide between total and near-liquefaction; indeed, when approaching liquefaction, the difference becomes small with respect to both pressures so it may be affected by small instrumental discrepancies like e.g. zero drift of the pressure cells. For example, in a preliminary publication (Servant, 2004), test CUSPR-03 was quoted as totally liquefied, but re-evaluating the data for the different tests, the authors consider that the most relevant indicator of total liquefaction with respect to nearliquefaction in the present case is more the final shape of the specimens.

In fact, the essential difference between the different cases is shown in Fig. 8 which presents the shape of the five specimens in the final state. In four among the five tests, the specimens remained solid after the unstable deformation phase, retaining the geometry of the final state when the testing machine was stopped. Only one test, namely CUSPR-02, was totally destroyed by the deformation underwent during the dynamic jump, and could not even be dismounted from the testing cell. This is what happens in common load-controlled tests along unstable loading paths: nothing can be said about the actual deformation process during the initiation of the catastrophic flow, because the only observable state is completely distorted.

What can be said from the observations illustrated by photographs presented in Fig. 8 is that the specimens CUSPR-01, CUSPR-03, CUSPR-04, and CUSPR-05 seem to have undergone a diffuse mode of plastic deformation during the dynamic step, without any obvious strain localizations (shear bands or localized zones). Nothing can be said from the photograph of specimen CUSPR-02, but there is no reason why the behaviour of these specimen would have been different in the initial stage of the dynamic failure. Indeed the difference in the final shape between this test and the others is that the amount of energy delivered by the spring in test CUSPR02 was larger, due to the low pre-stress force used in this specific case.

\section{DISCUSSION}

The above work was performed in order to investigate the modes of failure in geomaterials in undrained compression tests on very loose specimens of Hostun $S_{28}$ sand. No strain localization could be observed in any of the five specimens tested, so they are considered having undergone diffuse modes of failure. It should nevertheless be mentioned that in triaxial tests on loose, contracting sand specimens, it is usually difficult to decide whether a mode of failure is diffused or localized. Using X-Ray Computed Tomography on sand specimens tested in drained conditions, Desrues et al. (1996) have shown that complex strain localization patterns can be hidden to the naked eye observation of the outer membrane of the specimens. Thus a more extensive triaxial program is needed so as to verify and investigate the deformation of the specimen around the $q$ peak. Whether or not shear bands occur in tests in loose specimens, drained or undrained, in biaxial or axisymmetric triaxial or even in true triaxial tests, has been addressed by quite a few authors in the past, with contradictory results in fact. Lade et al. (1988) concluded that instabilitycharacterized by a runoff of stress-carrying capacity of the specimen-can occur in saturated loose sand prior to attaining the failure stress state, without formation of shear bands. Chu et al. (1993), performing tests with strain-path testing i.e. controlling the volumetric versus axial strain increment in axisymmetric triaxial tests report runaway instability occurring in an number of cases and indicate that in all instability tests, formation of shear bands did not occur. Han and Vardoulakis (1991) show that in undrained displacement-controlled biaxial tests on loose sand specimens no localization was observed, while for load controlled tests and for large strains the deformation localizes inside the rapidly deforming zone. Kato et al., in a study of undrained shear characteristics of saturated sand under anisotropic compression, using sands from contractive to dilative, report that at $30 \%$ axial strain, though shear bands was not observed in samples, there seem to be non-homogeneities in the strain distribution due mainly to friction at both ends of the sample. As for axisymmetric triaxial tests, De Gennaro et al. (2004), in a study of the influence of loading path on the undrained behavior of a medium loose sand, report undrained triaxial compression and extension tests, both strain-controlled and load-controlled, without any apparent necking or strain localization. Conversely, Mokni and Desrues (1999), in undrained displacement controlled biaxial tests, did observe localization in loose and very loose sand, occurring when the stress state reaches the line of maximum mobilized friction determined from drained tests on the same sand. Finno et al. (1996) in displacement-controlled undrained biaxial tests on loose sand observed localization also; they state that the stress state when the localization begins is very close to, yet precedes that corresponding to the maximum mobilized friction. In the early stages of the tests, they described non persistent shear bands. Finally, for load- 
controlled undrained test, the present study concludes to non-localized failure while Han and Vardoulakis (1991) reported localization occurring at large strain. From these different studies and probably a few other not cited in this brief overview, it appears that no agreement is found on the presence or absence of strain localization in the tests described involving loose sand specimens. However, it should be noted that the studies reporting no localization (including the present one) were performed without any special measuring effort to characterize strain field taking place within the specimens; the statement of absence of evidence of localization was founded on simple, direct naked-eye observation of the outer surface of the specimens. Conversely, the studies concluding to the presence of shear bands in the specimens were using advanced measuring methods, like X-ray photography (Han and Vardoulakis) or stereophotogrammetry (Mokni and Desrues, Finno et al.). Consequently, the conclusions drawn from the latter can be considered to have stronger foundations.

\section{CONCLUSION}

An experimental study was performed, using an original simple mechanical device, to investigate the modes of failure along unstable loading paths in undrained triaxial compression tests.

The concept of a spring-box device proved to be successful in that it allowed for recording specimen deformation even along unstable, dynamical paths. Indeed, we were able to perform actual unstable deformation increments in the unloading branch of the test in undrained liquefying specimens, still keeping the possibility to observe the kinematics of the specimen during these increments.

As far as the kinematics characterization is concerned, all five sand specimens apparently underwent diffuse modes of failure and no strain localization was observed with naked eye. It should nevertheless be mentioned that in a triaxial test it is usually difficult to decide whether a mode of failure is diffused or localized. One of the major deficit of the triaxial test, as far as the characterization of the mode of deformation is concerned, is the fact that the observation of the specimen during and after the test is limited to its outer boundary. Previous studies, using advanced full-field measuring techniques like X-ray tomography (Desrues et al., 1996), have shown that strain localization can remain hidden to the naked eye in such test conditions. An interesting direction to extend this study is to perform biaxial compression tests, where the modes of failure are easier characterized. Such tests could be, for example, performed in the biaxial apparatus proposed and designed by Vardoulakis and Drescher (1990) or in the biaxial apparatus developed and designed by Desrues (1985). Both of them allow for free shear band formation, while the second one in addition allows for full-field incremental strain measurement monitoring during the test.

\section{ACKNOWLEDGEMENTS}

The authors would like to acknowledge the EU project Degradation and Instabilities in Geomaterials with Application to Hazard Mitigation (DIGA) in the framework of the Human Potential Program, Research Training Networks (HPRN-CT-2002-00220).

\section{REFERENCES}

1) Alshibli, K. A., Batiste, S. N. and Sture, S. F. (2003): Strain localization in sand: Plane strain versus triaxial compression, J. Geotech. Engrg., ASCE, 129(6), 483-494.

2) Arthur, J. R. F. and Dunstan, T. (1982): Rupture layers in granular media, IUTAM Conf. Def. Fail. Gran. Media, (eds. by Vermeer, P. A. and Luger, H. J.), Balkema, 453-459.

3) Arthur, J. R. F., Dunstan, T., Al-Ani, Q. A. J. L. and Assadi, A. (1977): Plastic deformation and failure in granular media, Géotechnique, 27, 53-74.

4) Bardet, J. P. (1997): Experimental Soil Mechanics, Prentice Hall.

5) Bishop, A. W. and Henkel, D. J. (1957): The Measurement of Soil Properties in the Triaxial Test, Edward Arnold Ltd.

6) Chambon, R., Crochepeyre, S. and Desrues, J. (2000): Localization criteria for non linear constitutive equations of geomaterials, Mech. Coh. Frict. Mat., 5, 61-82.

7) Chu, J., Lo, S.-C. R. and Lee, I. K. (1993): Instability of granular soils under strain path testing, J. Geotech. Engrg., ASCE, 119(5), 874-892.

8) Combe, A.-L. (1998): Comportement du sable d' Hostun $S_{28}$ au triaxial axisymétrique, Comparaison avec le sable d' Hostun RF, Rapport de stage, University Joseph Fourier.

9) Darve, F. and Laouafa, F. (2000): Instabilities in granular materials and application to landslides, Mech. Coh. Frict. Mat., 5, 627-652.

10) De Gennaro, V., Canou, J., Dupla, J. C. and Benahmed, N. (2004): Influence of loading path on the undrained behaviour of a medium loose sand, Can. Geotech. J., 41, 166-180.

11) Desrues, J. and Chambon, R. (1989): Shear band analysis for granular materials: the question of incremental non linearity, Ingenieur Archiv., 59, 187-196.

12) Desrues, J. and Chambon, R. (2000): Shear band analysis and shear moduli calibration, Int. J. Solids Struct., 39, 13-14, 3757-3776.

13) Desrues, J. and Hammad, W. (1989): Shear banding dependency on mean stress level in sand, Proc. 2nd Int. Workshop on Localisation and Bifurcation, Gdansk, 57-68 (eds. by Dembicki, E., Gudehus, G. and Sikora, Z.), Techn. Univ. Gdansk.

14) Desrues, J. and Viggiani, G. (2004): Strain localization in sand: an overview of the experimental results obtained in Grenoble using stereophotogrammetry, Int. J. Num. Anal. Meth. Geomechanics, 28 (4), 279-321.

15) Desrues, J., Lanier, J. and Stutz, P. (1985): Localization of the deformation in tests on sand sample, Engrg. Fract. Mech., 21, 909-921.

16) Desrues, J., Chambon, R., Mokni, M. and Mazerolle, F. (1996): Void ratio evolution inside shear bands in triaxial sand specimens studied by computed tomography, Géotechnique, 46 (3), 529-546.

17) di Prisco, C., Imposimato, S. and Vardoulakis, I. (2000): Mechanical modeling of drained creep triaxial tests on loose sand, Géotechnique, 50 (1), 73-82.

18) Drescher, A. and Vardoulakis, I. (1982): Geometric softening in triaxial tests on granular material, Géotechnique, 32 (4), 291-303.

19) Drescher, A., Vardoulakis, I. and Han, C. (1990): A bi-axial apparatus for testing soils, Geotech. Test. J., GTJODJ, 13, 226-234.

20) Finno, R. J., Harris, W. W., Mooney, M. A. and Viggiani, G. (1996): Strain localization and undrained steady state of sands, $J$. Geotech. Engrg., ASCE, 122 (6), 462-473.

21) Gajo, A. (2004): The influence of system compliance on collapse of triaxial sand samples, Can. Geotech. J., 41, 257-273.

22) Gajo, A., Piffer, L. and De Polo, F. (2000): Analysis of certain 
factors affecting the unstable behaviour of saturated loose sand, Mech. Coh. Frict. Mat., 5, 215-237.

23) Han, C. and Vardoulakis, I. (1991): Plane-strain compression experiments on water-saturated fine-grained sand, Géotechnique, 41 (1), 49-78.

24) Harris, W. W., Viggiani, G., Mooney, M. A. and Finno, R. J. (1995): Use of stereophotogrammetry to analyze the development of shear bands in sand, Geotech. Test. J., GTJODJ, 18 (4), $405-420$.

25) Head, K. H. (1992): Manual of Soil Laboratory Testing, 3 Effective Stress Tests, John Wiley and Sons, Hill, R.

26) Kato, S., Ishihara, K. and Towhata, I. (2001): Undrained shear characteristics of saturated sand under anisotropic consolidation, Soils and Foundations, 41 (1), 1-11.

27) Lade, P. V., Nelson, R. B. and Ito, Y. M. (1988): Instability of granular materials with non associated flow, J. Engrg. Mech., ASCE, 114 (12), 2173-2191.

28) Mokni, M. and Desrues, J. (1999): Strain localization measurements in undrained plane-strain biaxial tests on Hostun RF sand, Mech. Coh. Frict. Mat., 4, 419-441.

29) Nova, R. (1994): Controllability of the incremental response of soil specimens subjected to arbitrary loading programmes, J. Mech. Behav. Mat., 5 (2), 193-201.

30) Rice, J. R. (1976): The localization of plastic deformation, Theoretical and Applied Mechanics (ed. by Koiter, W. T.), NorthHolland Publishing Company, 207-220.

31) Scott, R. F. (1987): Failure, Géotechnique, 37, 423-466.
32) Servant, G. D. F., Darve, F., Desrues, J. and Georgopoulos, I. O. (2004): Diffuse modes of failure in geomaterials, Deformation Characteristics of Geomaterials (eds. by Di Benedetto, Swets and Zeitlinger).

33) Tatsuoka, F., Sakamoto, M., Kawamura, T. and Fukushima, S. (1986): Strength and deformation characteristics of sand in plane strain compression at extremely low pressures, Soils and Foundations, 26 (1), 65-84.

34) Tatsuoka, F., Nakamura, T., Huang, C. C. and Tani, K. (1990): Strength anisotropy and shear band direction in plane strain test of sand, Soils and Foundations, 30 (1), 35-54.

35) Vaid, Y. P. and Sivathayalan, S. (2000): Fundamental factors affecting liquefaction susceptibility of sands, Can. Geotech. J., 37, 592-606.

36) Vardoulakis, I. and Graf, B. (1985): Calibration of constitutive models for granular materials using data from biaxial experiments, Géotechnique, 35 (3), 299-317.

37) Vardoulakis, I. and Sulem, J. (1995): Bifurcation Analysis in Geomechanics, Blackie.

38) Vardoulakis, I., Goldscheider, M. and Gudehus, Q. G. (1978): Formation of shear bands in sand bodies as a bifurcation problem, Int. J. Num. Anal. Meth. Geomech., 2, 99-128.

39) Yoshida, T., Tatsuoka, F., Siddique, M. S. A. and Kamegal, Y. (1994): Shear banding in sand observed in plane strain compression, Localization and Bifurcation Theory for Soils and Rocks (eds. by Chambon, R., Desrues, J., Vardoulakis, I.), Balkema, $165-179$. 